\title{
Aspects regarding the appreciation of regularity and punctuality in the public transport system from Sibiu, Romania
}

\author{
Carmen Purcar $^{1 *}$, Mircea Bădescu ${ }^{1}$, and Marinela Inţă $^{1}$ \\ 1'Lucian Blaga" University of Sibiu, Romania
}

\begin{abstract}
Regularity and punctuality are two very important measures for evaluating the quality of a public transport system. Several indicators can be used to estimate them, each with advantages and disadvantages. The paper comparatively describes a series of such indicators and presents a study conducted for two public transport lines in Sibiu, Romania. The study shows how, depending on the indicators used, the results show the influence of different factors.
\end{abstract}

\section{Indicators of punctuality and regularity}

When assessing the reliability of the public road transport system (indicating the extent to which the customer can be sure that the announced service will be provided [1]), reference is always made to the punctuality and regularity with which the buses arrive at the station.

Several indicators can be used to assess these parameters, described in the literature.

This paper aims to analyze aspects related to the punctuality and the regularity of buses on routes 1 and 2 in the city of Sibiu, Romania, making a comparison between known indicators, and to reveal their advantages and disadvantages.

There are several possibilities to appreciate the punctuality and regularity with which buses arrive at the station.

Below are several indicators that can be used for this purpose, as it results from the literature [2-10].

\subsection{Excess Wait time EWT}

The EWT [3] is calculated by the difference between the actual average headway on a given line and the scheduled average headway.

When the EWT is low, more passengers will perceive the service as a regular one and therefore will be more satisfied.

The calculation relation [3] is:

with : $\quad$ AWT - the actual average headway

$$
\text { EWT }=\text { AWT-SWT }
$$

\footnotetext{
* Corresponding author: carmen.purcar@ulbsibiu.ro
} 
EWT -the average scheduled headway

The average headways are calculated with the relations (2) şi (3)

$$
\begin{gathered}
A W T=\frac{\sum_{i=1}^{N} A H w a y_{i}^{2}}{2 \times \sum_{i=1}^{N} A H w a y_{i}} \\
S W T=\frac{\sum_{i=1}^{N} S_{W w a y_{i}^{2}}}{2 \times \sum_{i=1}^{N} S_{w a y_{i}}}
\end{gathered}
$$

with AHway =actual headway ;

SHway =scheduled headway;

$\mathrm{N}=$ the number of operations.

The advantages of this indicator are:

- it is easy to understand, being expressed in minutes

- includes all objectively measured data, including extreme data;

- focuses on customer perception, being expressed as extra waiting time for passengers.

As disadvantages, one can observe that if the scheduled headways are uneven, it can lead to altered results; in addition, relevant results are obtained only if the number of observations is high, otherwise, if the last observed bus comes earlier, the whole result changes artificially.

\subsection{Wait Assessment WA}

A reasonable range of variation of the headway is established - e.g. \pm 2 min from the default value - and it is determined how many of the actual headways fall within this interval (SHway $\pm 2 \mathrm{~min}$ ). The results are expressed in percentages and the higher the regularity, the higher the percentage.

The \pm 2 minute interval can be increased or decreased, depending on how long the scheduled headway is. For example, at headways of $5 \ldots 10$ minutes, intervals of \pm 2 minutes can be taken, but at a longer headways, eg $15 \ldots 20$ minutes, a longer interval can be considered acceptable, e.g. for \pm 4 minutes. Therefore, this indicator is more relevant when the scheduled headway is constant over the studied time interval.

In the same idea, the actual arrival time can be studied compared to the planned arrival time - WAP.

\subsection{Service regularity SR}

The scheduled headway is tolerated by an interval expressed in percentages, for example, equal to $\pm 20 \%$ of the scheduled headway and then proceed as in point 3 . The result is also expressed as a percentage and the same rule regarding the assessment of regularity is observed.

Indicators 3 and 4 have the advantage of being very easy to express and understand and also the width of the bands is easy to change and the results are easy to obtain. On the other hand, the width of the bands is set arbitrarily, based on previous experience, so they are not very objective indicators. They focus on the service and not on the perception of the passengers. They treat a very long delay in the same way as a small one, which is not correct from the point of view of the travelers. 


\subsection{Rhythmicity}

Rhythmicity assesses the impact on passengers of non-compliance with headways as set out in the timetable. It is calculated when the headway is at most $15 \mathrm{~min}$, otherwise it is not relevant. The rhythmicity coefficient $\mathrm{R}$ is calculated by the formula:

where:

$$
R=\sqrt{\frac{\sum_{i=1}\left(\frac{S H w a y_{i}-A H w a y_{i}}{W T_{i}}\right)^{2}}{N}}
$$

$\checkmark \quad \mathrm{SHway}_{i}=$ the scheduled headway between the bus i şi the previous bus i-1

$\checkmark \quad A_{H W a y}=$ the actual headway between the bus i şi the previous bus i-1

$\checkmark \quad \mathrm{N}$ - the number of operations scheduled in a day (or in the observed interval)

$\checkmark \mathrm{WTi}=$ an acceptable waiting time; it is taken according to the scheduled headway, SHwayi, this way:
$\checkmark$ if $\mathrm{SHway}_{\mathrm{i}} \leq 2 \mathrm{~min}$
then $\mathrm{WT}_{\mathrm{i}}=2 \mathrm{~min}$;
$\checkmark \quad$ if $2 \mathrm{~min}<\mathrm{SHway}_{\mathrm{i}}<10 \mathrm{~min}$ then $\mathrm{WT}_{\mathrm{i}}=\left(\mathrm{SHway}_{\mathrm{i}} / 2+1\right) \mathrm{min}$
$\checkmark \quad$ if $\mathrm{SHway}_{\mathrm{i}} \geq 10 \mathrm{~min} \quad$ then $\mathrm{WT}_{\mathrm{i}}=6 \mathrm{~min}$.

Appreciation of rhythmicity according to the value obtained for the coefficient $\mathrm{R}$ :

- if $0 \leq \mathrm{R}<0,2 \Rightarrow$ Rhythmicity is very good

- if $0,2 \leq \mathrm{R}<0,5 \Rightarrow$ Rhythmicity is good

- if $0,5 \leq \mathrm{R}<0,8=>$ Rhythmicity is bad

- if $\mathrm{R} \geq \Rightarrow$ Rhythmicity is very bad

\subsection{The punctuality Index}

In [5] there are defined 3 punctuality indexes: P1 as an index indicating the magnitude of the difference between the actual and the scheduled arrival time, P2 for the difference between the actual and the scheduled headways and P3 for the difference between the average headway of a day and each headway of successive buses.

The relations for the three indexes are as in Table 1.

Table 1. The Punctuality Indexes [5]

\begin{tabular}{|c|c|c|}
\hline Item & $\begin{array}{l}\text { Relation } \\
\end{array}$ & Variables \\
\hline P1 & $P_{1}=\frac{S_{1}^{2}}{h_{t}^{2}}$ & $\begin{array}{l}S_{1}^{2}=\frac{1}{N} \sum_{i=1}^{N}\left(H A_{i}-H S_{i}\right)^{2} \\
S_{2}^{2}=\frac{1}{N} \sum^{N}\left(\text { AHway }_{i}-\text { SHway }_{i}\right)^{2}\end{array}$ \\
\hline $\mathrm{P} 2$ & $P_{2}=\frac{S_{2}^{2}}{h_{t}^{2}}$ & $\begin{array}{l}S_{3}^{2}=\frac{1}{N-1} \sum_{i=2}^{N}\left(A H \text { way }_{i}-\bar{h}\right)^{2} \\
\text { AHway, SHway, } \mathrm{N}-\text { as defined earlier } \\
\text { HA - actual arrival time }\end{array}$ \\
\hline P3 & $P_{3}=\frac{S_{3}^{2}}{(\bar{h})^{2}}$ & $\begin{array}{l}\text { HS }- \text { scheduled arrival time } \\
\bar{h} \text { - the average headway of a day } \\
\bar{h}=\frac{1}{N-1} \times \sum_{i=2}^{N} H A_{i}-H A_{i-1}\end{array}$ \\
\hline
\end{tabular}


One can observe that the P3 index can also be calculated in the situation where there is no schedule for the arrival of buses at the station, a situation sometimes encountered in transports outside the locality, over very long distances (for example international car transports).

\subsection{The standard deviation of headway deviations $\sigma$}

The standard deviation [3] is calculated according to the actual headways AHway $_{i}$ and scheduled SHway, if the scheduled headways respect the normal distribution The relation is (5):

$$
\sigma=\sqrt{\frac{1}{N} \times \sum_{i=1}^{N}\left(\text { AHway }_{i}-S H w a y_{i}\right)^{2}}
$$

The advantages of this indicator lie in the fact that it is based on objective measurements, it is easy to understand, being expressed in minutes and all the data collected are used, although as output size, it indicates how punctuality is perceived by only $68 \%$ of passengers. Because it is a statistical parameter determined for a normal distribution, it is necessary to make many measurements and will be strongly influenced by any real long follow-up intervals.

\subsection{Coefficient of variation of headways, Cvh}

In [2] there is proposed that for headways smaller than $10 \mathrm{~min}$, to use in assessing the reliability a coefficient of variation of headways, $\mathrm{C}_{\mathrm{vh}}$

$$
C_{v h}=\frac{\text { standard deviation of headway deviations }}{\text { mean scheduled headway }}=\frac{\sigma}{\bar{h}}
$$

Standard deviation and the mean scheduled headway are the same defined at the other indicators.

This coefficient can be linked with the probability $\mathrm{P}$ expressed through the relation (7):

$$
P\left(\mid \text { AHway }_{i}-\text { SHway } \mid>0,5 \times \text { SHway }\right)
$$

Based on this probability, the authors of [2] define the level of service LOS, as one can see in Table 2 [2].

Table 2. LOS apreciated through $\mathrm{P}$ and $\mathrm{C}_{\mathrm{vh}}[2]$

\begin{tabular}{|c|c|c|c|}
\hline LOS & $\mathbf{C}_{\mathbf{v h}}$ & $\mathbf{P}$ (Ahway $\mathbf{>} \mathbf{1 , 5 S h w a y )}$ & Comments \\
\hline A & $0-0.21$ & $\leq 1 \%$ & Service provided like clockwork \\
\hline B & $0.22-0.30$ & $\leq 10 \%$ & Vehicles slightly off headway \\
\hline C & $0.31-0.39$ & $\leq 20 \%$ & Vehicles often off headway \\
\hline D & $0.40-0.52$ & $\leq 33 \%$ & Irregular headways \\
\hline E & $0.53-0.74$ & $\leq 50 \%$ & Frecvent bunching \\
\hline F & $\geq 0.75$ & $>50 \%$ & Most vehicles bunched \\
\hline
\end{tabular}

\subsection{Punctuality}

This indicator reflects the degree of compliance with the transit times as provided in the timetable, being an indicator that reflects the quality of compliance with the timetable, viewed especially from the point of view of the company that organizes the transport. It is an indicator frequently used in Romania. 
The calculation formula of the punctuality coefficient $\mathrm{P}$ is:

$$
\begin{gathered}
P=\sqrt{\frac{\sum_{i}\left(K_{i} \times E_{i}\right)^{2}}{N}} \\
\mathrm{E}_{\mathrm{i}}=\mathrm{HS}_{\mathrm{i}}-\mathrm{HA}_{\mathrm{i}}
\end{gathered}
$$

with: $\quad \mathrm{HS}_{\mathrm{i}}$ - arrival time provided in the schedule for the bus $\mathrm{i}$;

$\mathrm{HA}_{\mathrm{i}}$-arrival time observed by survey for bus $\mathrm{i}$

$\checkmark \quad \mathrm{K}_{\mathrm{i}}=$ coefficient by which the severity of the Ei gap is estimated (delay or arrival in advance). So if:

$$
\begin{array}{ll}
\checkmark & \mathrm{E}_{\mathrm{i}}<-1 \text { then } \mathrm{K}_{\mathrm{i}}=3 \\
\checkmark & \mathrm{E}_{\mathrm{i}}=[-1,0) \text { then } \mathrm{K}_{\mathrm{i}}=2 \\
\checkmark & \mathrm{E}_{\mathrm{i}}=[0 ; 1] \text { then } \mathrm{K}_{\mathrm{i}}=0 \\
\checkmark & \mathrm{E}_{\mathrm{i}}=>1 \text { then } \mathrm{K}_{\mathrm{i}}=1
\end{array}
$$

Appreciation of punctuality according to the value obtained for the coefficient $\mathrm{P}$ :

- if $\mathrm{P} \in[0 ; 0.5) \Rightarrow$ punctuality is considered to be very good

- $\quad$ if $P \in[0.5 ; 1) \Rightarrow$ punctuality is considered to be good

- $\quad$ if $P \in[1 ; 2)=>$ punctuality is considered unsatisfactory

- $\quad$ if $\mathrm{P} \geq 2 \Rightarrow$ punctuality is considered to be very bad

Each of the indicators analyzed above has its advantages and disadvantages, which is why one or the other of them may appear in different analyzes.

\section{Indicators determined in the city of Sibiu}

Sibiu is situated approximately in the center of Romania and has a surface of about 121 $\mathrm{km}^{2}$, with a population of about 170,000 inhabitants. The urban public transport network is served by 22 bus lines, which have a total length of approximately $138 \mathrm{~km}$.

For the present paper, some indicators presented above were calculated, on the same data set, in order to observe how the reality is perceived through each of them.

Because there are different headways $\left(h_{t}\right)$ at different hours, when calculating the $\mathrm{P}_{1}$ index it was necessary to replace $h_{\mathrm{t}}$ with $\bar{h}$.

For these calculations, two bus lines from Sibiu were surveyed: 1 and 2. These are the main lines in Sibiu and each of them has a length of about $10 \mathrm{~km}$. The 2 routes are shown in Figure 1 and Figure 2.

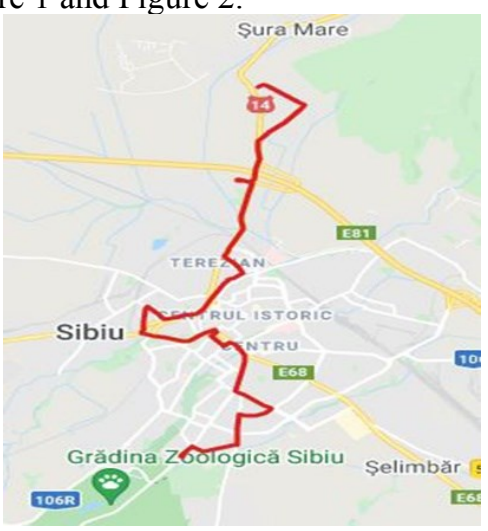

Fig. 1. Route 1

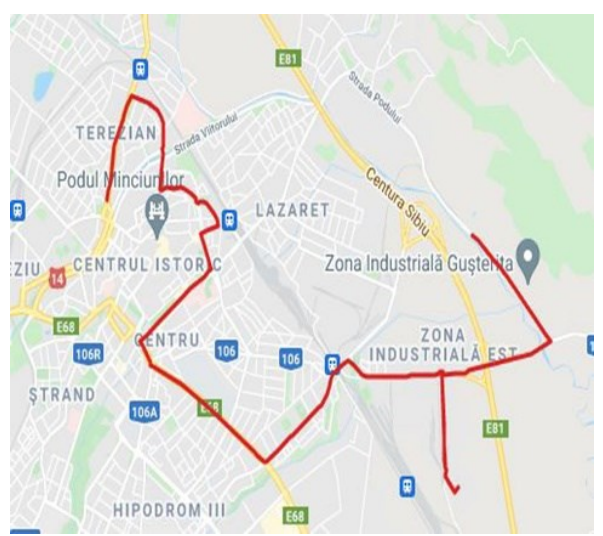

Fig. 2. Route 2 
The data were collected between 7:20 and 9:20, on July the $15^{\text {th }}, 16^{\text {th }}, 17^{\text {th }}, 18^{\text {th }}$ and $19^{\text {th }}$, 2019. These were working days and the hours correspond to the peak hours during the morning

Thus, for route 1, in the direction of Hornbach, the arrivals in Obor 2 station were observed (the 19th station in this direction out of the 26), and in the opposite direction, towards Calea Dumbrăvii, the arrivals in the station Aron Pumnul (24th station out of 27). On route 2, in the direction of Cibin Square, the station Gara was monitored (the 17th station out of 21), and in the opposite direction, towards Scandia - the Narcisa station (the 13th station out of 23). The stations were chosen to be located after the central area because here the highest values of traffic are recorded and therefore the long delays occur mainly in this area. The average distance between the stations is $512 \mathrm{~m}$ on line 1 and $592 \mathrm{~m}$ on line 2. The scheduled arrival times for each direction and the scheduled headway, in the mentioned interrval, are presented in Table 3. Data collection was done through the monitoring program of the local public transport company; the moment when the bus stops at the respective station was noted (deduced from the fact that its speed is at that moment $0)$.

Table 3. Scheduled arrival time and scheduled headway

\begin{tabular}{|c|c|c|c|c|c|c|c|}
\hline \multicolumn{4}{|c|}{ Line 1} & \multicolumn{4}{|c|}{ Line 2} \\
\hline \multicolumn{2}{|c|}{ Obor 2 Station } & \multicolumn{2}{|c|}{ Aron Pumnul Station } & \multicolumn{2}{|c|}{ Gara Station } & \multicolumn{2}{|c|}{ Narcisa Station } \\
\hline $\begin{array}{l}\text { Scheduled } \\
\text { arrival } \\
\text { time [min] }\end{array}$ & $\begin{array}{l}\text { Scheduled } \\
\text { headway } \\
\text { [min] }\end{array}$ & $\begin{array}{l}\text { Scheduled } \\
\text { arrival } \\
\text { time [min] }\end{array}$ & $\begin{array}{l}\text { Scheduled } \\
\text { headway } \\
\text { [min] }\end{array}$ & $\begin{array}{l}\text { Scheduled } \\
\text { arrival } \\
\text { time [min] }\end{array}$ & $\begin{array}{l}\text { Scheduled } \\
\text { headway } \\
\text { [min] }\end{array}$ & $\begin{array}{l}\text { Scheduled } \\
\text { arrival } \\
\text { time [min] }\end{array}$ & $\begin{array}{l}\text { Scheduled } \\
\text { headway } \\
\text { [min] }\end{array}$ \\
\hline $7: 21$ & \multirow{2}{*}{10} & $7: 40$ & \multirow{2}{*}{10} & $7: 22$ & \multirow{2}{*}{10} & $7: 23$ & \multirow{2}{*}{11} \\
\hline $7: 31$ & & $7: 50$ & & $7: 32$ & & $7: 34$ & \\
\hline $7: 44$ & 13 & $7: 55$ & 5 & 7:37 & 5 & $7: 43$ & 9 \\
\hline $7: 55$ & 11 & $8: 00$ & 5 & $7: 42$ & 5 & $7: 53$ & 10 \\
\hline $8: 05$ & 10 & $8: 05$ & 5 & $7: 47$ & 5 & $8: 01$ & 8 \\
\hline $8: 15$ & 10 & $8: 17$ & 12 & $7: 52$ & 5 & $8: 11$ & 10 \\
\hline $8: 27$ & 13 & $8: 27$ & 10 & $8: 03$ & 9 & $8: 19$ & 8 \\
\hline $8: 35$ & 8 & $8: 37$ & 10 & $8: 14$ & 11 & $8: 29$ & 10 \\
\hline $8: 45$ & 10 & $8: 47$ & 10 & $8: 25$ & 11 & $8: 39$ & 10 \\
\hline $8: 55$ & 10 & 9:00 & 13 & $8: 36$ & 11 & $8: 49$ & 10 \\
\hline 9:05 & 10 & 9:07 & 7 & $8: 47$ & 11 & $8: 59$ & 10 \\
\hline \multirow[t]{3}{*}{$9: 15$} & 10 & 9:17 & 10 & $8: 58$ & 11 & 9:09 & 10 \\
\hline & & & & 9:09 & 11 & $9: 20$ & 11 \\
\hline & & & & $9: 20$ & 11 & & \\
\hline
\end{tabular}

The data were collected in the format of hour: min: sec, a sequence occurring in Figure 3.

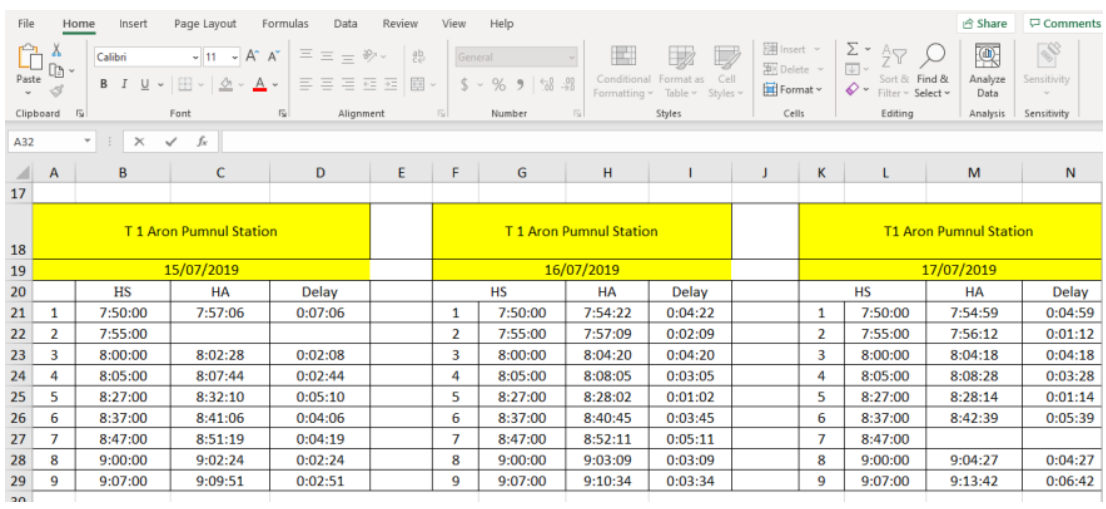

Fig. 3. Sample data collected from T1 
The results of the calculations are summarized in Table 4 .

It is stated that for the Wait Assessment, the interval of \pm 2 min was taken (in [2], [3] and [11] this is considered to be an appropriate value for a follow-up time of approximately 10 minutes, as is the case studied, although other intervals can be taken), and for the Rhythmicity, the value of $\pm 20 \%$ of the predetermined follow-up interval was considered (from $[12,13])$.

Table 4. The calculated indicators

\begin{tabular}{|c|l|c|c|c|c|c|c|c|}
\hline \multirow{3}{*}{ Route } & \multirow{2}{*}{ Station } & \multicolumn{7}{|c|}{ Indicator value } \\
\cline { 3 - 9 } & $\begin{array}{c}\text { EWT } \\
{[\mathbf{m i n}]}\end{array}$ & $\boldsymbol{\sigma}[\mathbf{m i n}]$ & $\begin{array}{c}\text { WA } \\
{[\%]}\end{array}$ & $\mathbf{R}$ & $\begin{array}{c}\text { WAP } \\
{[\%]}\end{array}$ & P & $\begin{array}{c}\mathbf{P}_{\mathbf{1}} \\
{[\%]}\end{array}$ \\
\hline \multirow{2}{*}{1} & Aron Pumnul & 0,65 & 3,74 & $36 \%$ & 3,61 & $54 \%$ & 48.31 & $82 \%$ \\
\cline { 2 - 9 } & Obor 2 & 0,48 & 4,12 & $77 \%$ & 0,53 & $77 \%$ & 18.81 & $69 \%$ \\
\hline \multirow{2}{*}{2} & Gară & 0,14 & 2,71 & $52 \%$ & 0,64 & $34 \%$ & 8.95 & $56 \%$ \\
\cline { 2 - 9 } & Narcisa & 0,10 & 1,27 & $82 \%$ & 0,26 & $79 \%$ & 2.33 & $34 \%$ \\
\hline
\end{tabular}

\section{Interpretation of the obtained values}

In order to observe how the different indicators reflect the reality, the stations will be ranked in terms of regularity and punctuality. Thus, the 1st place will be represented by the station that is in the best situation, the 4 th place being the least appropriate. The situation is described from the point of view of each indicator in Table 5.

Table 5. Stations ranking

\begin{tabular}{|c|c|c|c|c|c|c|c|c|}
\hline \multirow{3}{*}{ Route } & \multicolumn{7}{|c|}{ Indicator value } \\
\cline { 3 - 9 } & Station & $\begin{array}{c}\text { EWT } \\
{[\mathbf{m i n}]}\end{array}$ & $\begin{array}{c}\text { Sigma } \\
\mathbf{\sigma} \\
{[\mathbf{m i n}]}\end{array}$ & $\begin{array}{c}\text { WA } \\
{[\%]}\end{array}$ & $\mathbf{R}$ & $\begin{array}{c}\text { WAP } \\
{[\%]}\end{array}$ & $\mathbf{P}$ & $\begin{array}{c}\mathbf{P}_{\mathbf{1}} \\
{[\% \mathbf{\%}}\end{array}$ \\
\hline \multirow{2}{*}{1} & A.Pumnul & 4 & 3 & 4 & 4 & 3 & 4 & 4 \\
\cline { 2 - 10 } & Obor 2 & 3 & 4 & 2 & 2 & 2 & 3 & 3 \\
\hline \multirow{2}{*}{2} & Gară & 2 & 2 & 3 & 3 & 4 & 2 & 2 \\
\cline { 2 - 10 } & Narcisa & 1 & 1 & 1 & 1 & 1 & 1 & 1 \\
\hline
\end{tabular}

One can observe that the WA and R indicators offer the same ranking for the regularity and the same way do $\mathrm{P}$ and $\mathrm{P}_{1}$ for the punctuality.

EWT offers a little modified ranking, while WAP shows a totally different ranking in relation with $\mathrm{P}$ and $\mathrm{P}_{1}$ - because there are a lot of big delays and SR doesn't take into ocount the size of the delay.

Sigma also offers a different image, but probably because of the little size of the sample.

Based on these results and on the observations made at the presentation of the indicators, it can be recommended to use $\mathrm{P}_{1}$ or $\mathrm{P}$ indicators in the analysis of punctuality aspects of a lot of data collected. For the regularity, we would recommend WA, which is very easy to understand, although when are several different headways it is not easy to choose the confidence interval. $\mathrm{R}$ is more accurate but not very easy to understand how critic is the rhythmicity. From this point of view, it is easier to understand EWT, which is expressed in minutes.

The two indicators, WA and WAP refer especially to the regularity with which the vehicles arrive at the station, treating in the same way the long delays as the small ones, which provides information incomplete on customer perception. 


\section{References}

1. SREN 13816:2003

2. TCRP 2003. Transit Capacity and Quality of Service Manual, (2003)

3. M. Trompet, X. Liu, DJ. Graham, Transp. Res. Rec. 2216(1), 33 (2011)

4. G. Henderson, P. Kwong, and H. Adkins, Transp. Res. Rec.1297 (1991)

5. N. Yaakub and M. Napiah, Eur. J. Environ. Civ. Eng. 5, 783 (2011)

6. G. Currie, N.J. Douglas and I. Kearns, Australasian Transport Research Forum 2012 Proceedings (2012)

7. L. Eboli, G. Mazzulla, European Transport 51, 4, (2021)

8. Seung-Young Kho, Jun-Sik Park, Young-Ho Kim, Eun-Ho Kim, J. East Asia Soc. Transp. Stud. 6, 492 (2005)

9. O. Cats, Transp Policy 36, 223 (2014)

10. M. Napiah, I. Kamaruddin \& Suwardo, WIT Transactions on The Built Environment, 116, $215(2011)$

11. M. Inţă, A. Muntean, Annals of the Oradea University, Fascicle of Management and Technological Engineering, 1, 79 (2015)

12. N. Carrasco, Transp. Res. Rec., 2274 (1), 114 (2021)

13. L. Redman, M. Friman, T. Garling, T. Hartig, Transp Policy 25, 119 (2013) 